Gut, 1986, 27, S1, 51-55

\title{
Complications of enteral nutrition
}

\author{
M D BASTOW \\ From the University Department of Medicine, Manchester Royal Infirmary, Manchester
}

SUMmaRY Complications may arise during enteral feeding that are usually related to the diameter and rigidity of the tube or the delivery, composition, and sterility of the feed uses. By using a soft, fine bore tube to deliver a sterile feed of known composition, by continuous infusion rather than as a bolus, most of these complications can be avoided.

The enteral route can be used to feed most patients, both in hospital and at home, who are unable or unwilling to eat amounts to suffice their daily needs. The route is both safer and cheaper to use than its technically more glamorous brother, the parenteral route. The time honoured method used for enteral feeding has been to pass a large bore tube (such as Ryle's) into the stomach, and intermittently to pour or pump a liquid feed of variable composition down the tube. Using this method patients have been fed for over 100 years, ' but problems may arise, particularly in relation to the technique used. Usually, however, these can be overcome.

\section{Mechanical or tube related problems}

When a wide bore tube of the Ryle type is used for nasogastric feeding, the size and rigidity of the tube tends to produce irritation and inflammation along its course and to encourage gastroesophageal reflux. By the simple expedient of using a soft, fine bore tube, clinical experience suggests that most of these problems can be avoided, but comparative studies have not been conducted. Although the advantages of using a fine bore tube were recognised in 1952,2 it is disheartening to see how often patients are still fed nasogastrically through rigid large bore tubes.

Fine bore tubes are prone to coil up in the oropharynx or to wander off course into the trachea during insertion, particularly in unconscious patients. ${ }^{3}$ Although perforation of the nasopharynx,${ }^{4}$ oesophagus, ${ }^{5}$ stomach,${ }^{6}$ and transbronchial insertion into the pleural space ${ }^{7}$ have been described during fine bore tube insertion, it must be emphasised that these complications are rare. Because of the

Correspondence to: Dr M D Bastow. Department of Medicine. Manchester Royal Infirmary. Oxford Road, Manchester M13 9WI.. England. risk of misplacement, however, it is important to ensure correct positioning of the tube before feeding is started (the small internal diameter of fine bore tubes usually prevents aspiration of the stomach contents) and to check the position of the tube with litmus paper. Insufflating air down the tube and auscultating over the epigastrium ${ }^{8}$ for the sound of bubbling can be used, although occasionally a tube can be passed into the trachea in the presence of copious bronchial secretions without being detected by this method. Confirmation by radiograph is the surest method, but this is associated with the problems of radiation exposure, particularly when patients require frequent reintubation.

A further problem encountered when using fine bore tubes is the ease with which the end of the tube can ride up into the oesophagus during feeding - up to $50 \%$ of tubes require replacement at some time during the period of feeding because they become misplaced or are removed completely. ${ }^{9}$ This tendency to dislodge does not seem to be reduced by using weighted tubes, ${ }^{9}{ }^{10}$ except in patients with disordered gastric emptying, in whom weighted tubes inserted endoscopically into the duodenum may remain in situ for longer than unweighted tubes. ${ }^{11}$

The small internal diameter of fine bore tubes also prevents aspiration with a syringe to check stomach emptying, particularly when feeds prone to curdling are used, ${ }^{12}$ and for this reason, when in doubt, a large bore (such as Ryle's) tube should be passed initially and the stomach aspirated every four hours, until it is confirmed that emptying is occurring: only then should feeding be started. ${ }^{8}$ The small diameter also limits flow rate and hence feed delivery, particularly with high viscosity feeds. ${ }^{12}$ This may be a problem with patients who require a high calorie and nitrogen intake, but various different tube sizes are now available, and a good compromise between flow rate and size related side effects can usually be 
achieved. The design of fine bore tubes is under continuous development, and hopefully, some of these mechanical problems will soon be overcome.

\section{Gastrointestinal complications}

Gastrointestinal side effects are among the most commonly reported in patients receiving enteral nutrition - in some series occuring in over $25 \%$ of the patients fed. ${ }^{13-15}$

\section{NAUSEA AND VOMITING}

Nausea, vomiting, bloating and abdominal cramps may occur in $10-15 \%$ of patients. ${ }^{16}$ These symptoms are particularly likely to occur when feeds with a high energy content are given as a bolus ${ }^{16} 17$ and when "elemental" diets are used. Patients with the nephrotic syndrome and other causes of oedema of the intestinal mucosa are also at increased risk of gastrointestinal side effects (personal observation).

\section{DIARRHOEA}

Diarrhoea is the side effect most often associated with nasogastric tube feeding. ${ }^{18}$ The aetiology of the diarrhoea is complex, but it is now clear that two major causes are concomitant antibiotic treatment $^{1619}$ and bolus delivery of the feed. ${ }^{13} 17$

The mechanisms by which oral (and occasionally parenteral) antibiotics produce diarrhoea in enterally fed patients is not clear, but overgrowth with Clostridium difficile and the lactose content of the diet are rarely implicated. ${ }^{20}$ Changes in normal intestinal flora, brought about by the antibiotic, may change the fatty acid composition of the intestinal contents, and this in turn may adversely affect colonic sodium and water handling.

The delivery of a liquid feed as a bolus into the stomach induces rapid and uncontrolled emptying into the small bowel with fast transit through the small bowel. This tends to produce diarrhoea. ${ }^{1721}$ If, however, a constant infusion rate is used gastric emptying is delayed and more regulated from the beginning of feeding, ${ }^{17}$ thus reducing the likelihood of diarrhoea. By the simple expedient of administering the feed continuously rather than as a bolus intermittently, the likelihood of diarrhoea developing can be considerably reduced. ${ }^{13}$

High osmolality of the feed has often been proposed as a cause of diarrhoea and abdominal discomfort, but our experience ${ }^{23} 24$ and that of others ${ }^{16}$ suggests that feeds of up to $600 \mathrm{mOsmol} / \mathrm{kg}$ can be given to patients without inducing gastrointestinal symptoms, provided administration is continuous rather than intermittent.

Feeds containing high lactose have a particularly bad reputation for producing diarrhoea. Inherited lactase deficiency occurs in about $6 \%$ of English patients $^{22}$ and a much higher proportion of noncaucasean Europeans, ${ }^{25}$ but these subjects may often tolerate a surprisingly high lactose intake ${ }^{26}$ without developing diarrhoea. Illness and malnutrition may temporarily depress mucosal lactase activity, ${ }^{27} 28$ leading to a reduction in the capacity to hydrolyse lactose; and any unabsorbed lactose might then be expected to produce diarrhoea, but again this is not usually a problem in clinical practice, provided the feed is administered continuously.

Diets containing large quantities of fat, including medium chain triglycerides, may sometimes produce diarrhoea, particularly when luminal fat digestion is impaired. 29.30

The administration of a cold feed - for example, straight from the fridge - has been reported to produce abdominal cramps and diarrhoea, ${ }^{31}{ }^{32}$ but the risk of bacterial contamination and multiplication during any warming procedure outweigh any benefit, ${ }^{59}$ and so prewarming is not recommended.

If diarrhoea remains a problem after any of the correctable causes have been identified and attended to then symptomatic treatment with codeine phosphate is usually effective. ${ }^{13}$ It is rarely necessary to stop enteral feeding because of diarrhoea.

\section{CONSTIPATION}

Patients on long term enteral nutrition may develop constipation, particularly if they become dehydrated or when a low lactose feed is used. This can be managed in the conventional manner: there is no evidence to suggest that the addition of fibre to the enteral feed is beneficial.

\section{Metabolic complications}

Metabolic problems may arise during enteral feeding by injudicious choice of feed and remain undetected by lack of adequate monitoring.

\section{DEHYDRATION AND HYPERGLYCAEMIA}

In the past nasogastric tube feeds of a very high osmolality (about $1000 \mathrm{mOsmol} / \mathrm{kg}$ ) with a high protein content were often used. These feeds occasionally produced dehydration with hypernatraemia and uraemia, ${ }^{33}{ }^{34}$ as the maximal renal concentrating ability may be considerably reduced by ill health, and in the elderly ${ }^{35}{ }^{36}$ the ability to excrete the solute load from these high protein feeds is severely limited. The use of feeds of osmolality 300-600 $\mathrm{mOsmol} / \mathrm{kg}$ should avoid this problem, but it remains important to monitor patients for evidence of dehydration, particularly those who are elderly or who are unable to respond to, or signal, their thirst.

Hyperglycaemia may occur during enteral feeding 
because of the high carbohydrate content of some nasogastric feeds and because of the relative insulin resistance that occurs with illness. ${ }^{13.37}$ Rarely does hyperglycaemia produce dehydration severe enough for hyperosmolar coma to develop, ${ }^{38}$ hence the importance of regular monitoring: if hyperglycaemia is found then insulin should be administered, using a regimen such as that described by Woolfson. ${ }^{39}$

\section{ELECTROLYTE ABNORMAIITIES}

Electrolyte abnormalities, particularly hypokalaemia and hyperkalaemia, may occur during enteral feeding, but careful monitoring (especially of patients receiving concomitant insulin treatment ${ }^{4(1)}$ ) and attention to the potassium content of the feed ${ }^{41}$ should prevent serious departures from the normal range.

The sodium content of proprietary feeds is very variable, and additional sodium may need to be added, particularly with defined formula diets.

Hypophosphataemia may occur in relation to illness and insulin treatment ${ }^{40}$ but responds to supplementation.

VITAMIN AND TRACE ELEMENT DEFICIENCES Commercial feeds are designed to contain adequate amounts of vitamins and trace elements, but there is variation between individual products, ${ }^{42}$ and it must be borne in mind that the requirements for vitamins and minerals during illness are not known. Occasional problems have arisen with the high vitamin $\mathrm{K}$ content of some feeds when given to patients who are anticoagulated ${ }^{43}$ with warfarin.

\section{ABNORMALITIES OF LIVER FUNCTION TESTS}

Abnormal liver function tests have been reported in patients receiving enteral nutrition. ${ }^{44} 45$ The changes include increases in alkaline phosphatase, $\gamma$ glutamyl transpeptidase, and hepatocellular enzyme activities. The cause of these changes is uncertain, ${ }^{44}$ and most return to normal when feeding is stopped. It is not usually necessary to stop the feeding because of these changes. ${ }^{28}$

\section{Infectious complications}

Potentially, the most serious complications that can arise during enteral feeding are aspiration of the feed into the lungs and bacterial contamination of the feed. ${ }^{59}$

Regurgitation and aspiration of feed is a potentially serious complication in all patients fed nasogastrically. The feed may be regurgitated while the tube is in the stomach; the end of the tube may become dislodged and ride up into the oesophagus; or inadvertent nasotracheal intubation may occur at the time the tube is inserted. Some patients are particularly at risk for regurgitation and aspiration of feed: those who are paralysed and mechanically ventilated; those with large bore tubes in situ; and those who are conscious but have an impaired cough reflex. ${ }^{40-49} 51$

Recognition of this serious complication can be difficult: the sudden onset of respiratory distress following the start of feeding or after an observed aspiration is relatively easy; but regurgitation can occur silently with only the development of tachypnoea, tachycardia, fever, hypoxia and hypercapnia, respiratory acidosis, or radiograph changes to arouse suspicion. Establishing the diagnosis with certainty is also difficult. Adding methylene blue to the feed and checking the colour of the pulmonary secretions ${ }^{46}$ or testing for glucose in the pulmonary secretions ${ }^{50}$ have been proposed but are not reliable, and if doubt remains then feeding should probably be stopped.

Treatment of feed aspiration consists of stopping the feeding and trying to remove as much of the aspirate as possible; by applying suction to the nasogastric tube, physiotherapy, tracheal suction and bronchoscopy. Treatment with positive pressure ventilation in those not already receiving it may be beneficial in the case of a large volume aspiration.$^{52}$ The role of steroids is controversial, but most evidence suggests that unless they are given within minutes of the event they are of no benefit and may actually be harmful. ${ }^{53}{ }^{54}$ Pulmonary infections may follow aspiration, and treatment with antibiotics, if indicated, should include agents active against anaerobic organisms. ${ }^{55}$

Several measures can be taken to decrease the likelihood of feed aspiration: raising the head of the bed; ensuring the adequacy of gastric emptying; and avoiding the use of high energy content feeds that might delay gastric emptying may help. Patients who are endotrachealy intubated and receiving positive pressure ventilation, however, remain at risk from this potentially serious complication.

Duodenal intubation with a long weighted tube or the use of a jejunostomy ${ }^{56}$ may be helpful. The use of a gastrostomy ${ }^{57}$ or pharyngostomy ${ }^{58}$ does not overcome the risk of aspiration in these patients.

\section{Conclusion}

Many of the problems encountered with enteral feeding can largely be avoided by using a fine bore tube, administering the feed by continuous infusion, and by careful monitoring of the patient for metabolic abnormalities. Fine bore tubes are easily misplaced or dislodged from the stomach, and it is important to ensure correct positioning both before 
and during feeding. It is hoped that further developments in tube design will reduce this problem.

\section{References}

1 Clouston TS. Forcible feeding. Lancet 1872: 797-8.

2 Fallis LS, Barron J. Gastric and jejunal alimentation with fine polyethylene tubes. Arch Surg 1952; 83: 147-60.

3 Sweatman AJ, Tomasello PA, Houghhead MG, et al. Misplacement of nasogastric tubes and oesophageal monitoring devices. Br J Anaesth 1978; 50: 389-92.

4 Siemers PT, Reinke RT. Perforation of the nasopharynx by nasogastric intubation: a rare cause of left pleural effusion and pneumomediastinum. Am J Radiol 1976; 127: 341 .

5 James RH. An unusual complication of passing a narrow-bore nasogastric tube. Anaesthesia 1978; 33: 716.

6 Ghahremain GG, Turner MA. Port RB. Iatrogenic intubation injuries of the upper gastro-intestinal tract in adults. Gastrointest Radiol 1980; 5: 1-10.

7 Hand RW, Kempster M, Levy JH, Rogol PR, Spirn P. Inadvertant trans-bronchial insertion of narrow-bore feeding tubes into the pleural space. JAMA 1978; 251: 2396-7.

8 Allison SP, Walford S, Todorovic V, Elliot ET. Practical aspects of nutritional support. Developments in clinical nutrition. Research and Clinical Forums 1979; 1.1: $48-57$.

9 Keohane PP, Attrill H, Jones BJM, Silk DBA. Limitations and drawbacks of 'fine bore' nasogastric feeding tubes. Clin Nutr 1983; 2: 85-6.

10 Crocker K, Krey S, Steffee W. Performance evaluation of a new nasogastric feeding tube. JPEN 1981; 1: 80-2.

11 Keohane PP, Attrill H, Silk DBA. Clinical indications for weighted enteral feeding tubes. Clin Nutr 1983; 2: 25-6.

12 Elia M, Crozier C, Martin S, Neale G. Flow and aspiration of artifical feeds through nasogastric tubes. Clin Nutr 1984; 2: 159-66.

13 Woolfson AMJ, Ricketts CR, Hardy SM, Saour JN, Pollard BJ, Allison SP. Prolonged nasogastric tube feeding in critically ill and surgical patients. Postgrad Med J 1976; 52: 678-82.

14 Heymsfield SB, Bethel RA, Ansley JD, Nixon DW, Rudman D. Enteral hyperalimentation: an alternative to central venous hyperalimentation. Ann Intern Med 1979; 90: 63-71.

15 Jones BJM, Lees R, Andrews J, Frost P, Silk DBA. Comparison of an elemental and polymeric enteral diets in patients with normal gastrointestinal function. Gut 1983; 24: 78-84.

16 Keohane PP, Attrill H, Love M, Frost P, Silk DBA. Relation between osmolality of diet and gastro intestinal side effects in enteral nutrition. Br Med $J$ 1984; 288: $678-80$.

17 McHugh P, Moran T. Calories and gastric emptying: a regulatory capacity with implications for feeding. Am J Physiol 1979; 236: 254-60.

18 Peaston MJT. Maintenance of metabolism during intensive patient care. Postgrad Med J 1967; 43: 317-38.

19 Bastow MD, Rawlings J, Allison SP. Benefits of supplementary tube feeding after fractured neck of femur: a randomised controlled trial. Br Med J 1983; 287: 1589-92.

20 Keohane PP, Attrill H, Jones BJM, Brow I, Frost P, Silk DBA. The roles of lactose and clostridium difficile in the pathogenesis of enteral feeding associated diarrhoea. Clin Nutr 1983; 1: 259-64.

21 Johansson C. Studies of gastrointestinal interactions. Scand J Gastroenterol 1974; 9 (Suppl): 1-60.

22 Neale G. Defects of sugar absorption. The diagnosis, incidence and significance of disaccharidase deficiency in adults. Proceedings of the Royal Society of Medicine 1968; 61: 1099-102.

23 Allison SP. Latest practical aspects of enteral feeding. In: Wesdorp RIC, Soeters PB, eds. Clinical nutrition '81. London: Churchill Livingstone, 1982: 133-9.

24 Bastow MD, Rawlings J, Allison SP. Overnight nasogastric tube feeding at home and in hospital. Clin Nutr 1985; 1(4): 7-11

25 Simoons FJ. Primary adult lactose intolerance and the milking habit: a problem of biologic and cultural interactions. 1. Review of the medical research. $A m J$ Dig Dis 1969; 14: 819-64.

26 Passmore R. Clinical importance of lactase deficiency. New Engl J Med 1984; 311: 56.

27 McMichael HB, Webb J, Dawson AM. Jejunal disaccharidases and some observations on the cause of lactase deficiency. $B r$ Med $J$ 1966; 2: 1037-41.

28 McMichael HB. Clinical studies of carbohydrate digestion and absorption in man. Transactions of the Biochemical Society 1975; 3: 223-30.

29 Chernoff R. Enteral feedings. Am J Hosp Pharm 1980; 37: $65-74$.

30 Silk BDA, Enteral nutrition. Postgrad Med J 1984; 60: 779-90.

31 Kagawa-Busby KS, Heitkemper MM, Hansen BC, Hanson RL, Vandderburg VV. Effects of diet temperature on tolerance of enteral feeding. Nurs Res 1980; 29: 276-80.

32 Broom J, Jones $\mathrm{K}$. Causes and prevention of diarrhoea in patients receiving enteral nutritional support. Journal of Human Nutrition 1981; 35: 123-7.

33 Engel FL, Jaeger C. Dehydration with hypernatraemia, hyperchloraemia and azotaemia. Complicating nasogastric tube feeding. Am J Med 1954; 17: 196-204.

34 Anonymous. Hypernatraemia in tube-fed patients. [Editorial]. $\mathrm{Br}$ Med J 1963; i: 1179-80.

35 Isaccson LC. Urinary osmolality in thirsty normal subjects. Lancet 1960; 1: 467-9.

36 Anonymous. Thirst and osmoregulation in the elderly. [Editorial]. Lancet 1984; ii: 1017-18.

37 Allison SP, Hinton P, Chamberlain MJ. Intravenous glucose tolerance, insulin and free fatty acid levels in burned patients. Lancet 1968; ii: 1113-16.

38 Brenner WI, Lansky Z, Engleman RM, Stahl WM. Hyperosmolar coma in surgical patients: An iatrogenic 
disease of increasing incidence. Ann Surg 1973; 178: $651-4$.

39 Woolfson AMJ. An improved method for blood glucose control during nutritional support. JPEN 1981; 5: $436-40$.

40) Vanlandingham S, Simpson S, Daniel P, Newmark SR Metabolic abnormalities in patients supported with enteral tube feeding. JPEN 1981; 5: 322-4.

41 Primrose JN, Carr KW, Sim AWJ, Shenkin A. Hyperkalaemia in patients on enteral feeding. JPEN 1981; 5: 130-1.

42 Bunker VW, Clayton BE. Trace element content of commercial enteral feeds. Lancet 1983; ii: 426-8.

43 Watson AJM, Pegg M, Green JRB. Enteral feeds may antagonise warfarin. $\mathrm{Br}$ Med $J$ 1984; 288: 557.

44 Zarchty TM, Lipman TO, Finkelstein JD. Elevated transaminases associated with an elemental diet. Ann Intern Med 1978; 89: 221-2.

45 Tweedale DEF, Skidmore FD, Gleave EN, Knass DA, Gowland E. Nutritional support for patients undergoing surgery for cancer of the head. Research and Clinical Forums 1979; 1.1: 59-67.

46 Cameron JL, Reynold J, Znidema G. Aspiration in patients with tracheostomies. Surg Gynecol Obstet 1974; 136: 68-70.

47 Spray SB, Znidema GD, Cameron JL. Aspiration pneumonia: incidence of aspiration with endotracheal tubes. Am J Surg 1976; 131: 701-3.

48 Johnston IDA, Lee HA. Developments in clinical nutrition. Research and Clinical Forums 1979; 1.1: 110.
49 Boscoe MJ, Rosin MD. Fine bore enteral feeding and pulmonary aspiration. $\mathrm{Br}$ Med $J$ 1984; 289: 1421-2.

50 Winterbauer RH, Durning RB, Barron E, McFadden MC. Aspirated nasogastric feeding solution detected by glucose strips. Ann Intern Med 1981; 95: 67-8.

51 Schorlemmer GR, Battaglini JW. An unusual complication of nasoenteral feeding with small-diameter feeding tubes. Am Surg 1984; 199: 104-6.

52 Broe PJ, Toung TJK, Cameron JL. Aspiration pneumonia. Surg Clin North Am 1980; 60: 1551-64.

53 Wynne JW, DeMarco FJ, Hood I. Physiological effects of corticosteroids in food stuff aspiration. Arch Surg 1981; 116: 46-9.

54 Wolfe JE, Bone RC, Ruth WE. The effects of corticosteroids in treatment of patients with gastric aspiration. Am J Med 1977; 63: 719-22.

55 Lorber B, Swenson RM. Bacteriology of aspiration pneumonia. A prospective study of community and hospital-acquired cases. Ann Intern Med 1974; 81: 324-31.

56 Sawyer RB. Jejunostomy for feeding or decompression. Surg Clin North Am 1969; 49: 1311-16.

57 Engel S. Gastrostomy. Surg Clin North Am 1969; 49: 1289-95.

58 Fitz-Hugh GS, Sly DE. Elective cervical esophagostomy. Ann Otol Rhinol Laryngol 1967; 76: 804-9.

59 Anderton A. Microbiological aspects of the preparation and administration of nasogastric and nasoenteric tube feeds in hospital-A review. Hum Nutr Appl Nutr 1983; 37A: 426-40. 